\title{
Toward new comparative understandings
}

It is easy to concur with the positive expectations for the International Journal of Alcohol and Drug Research (IJADR) expressed in the other editorials in this first issue. I would add, as a long-time editor of a small journal, that I have come to the firm conclusion that the presence of more journals can only benefit a field of research, provided the journals have quality control and follow basic publication ethics. Thus, one more good journal means a more informed scientific debate within the whole substance use research field, enriched by one more perspective. I sincerely believe that IJADR will not compete with but will instead strengthen journals such as the African Journal of Drug and Alcohol Studies, which in the future will have one more natural discussion partner.

As well, I hope that IJADR will follow the spirit of the Kettil Bruun Society (KBS) and be a journal able to stimulate inquisitive research and provide a forum for discussion, in an atmosphere of mutual respect and openness between researchers, where cultural, economic, status, age or gender differences are regarded as inviting challenges rather than as obstacles.

KBS aims, as its by-laws state, to promote "a comparative understanding of the social aspects of alcohol use and alcohol problems . . . [and] a spirit of international cooperation." Many members of the society have had central roles in influential international research projects on consumption, policies and other aspects of substance-related problems. Some of these projects, such as GENACIS, have truly been KBS projects; others have built on networking among members.

The launching of the KBS journal comes soon after the first thematic KBS meeting on the African continent, in Kampala in 20I0, and the year after the society's 2OII annual meeting in Melbourne, where there was an unprecedented presence of both African and Asian researchers. IJADR can be regarded as another sign of a new internationalism within the society, manifested in this first issue with articles from the meeting in Kampala.
The broadened geographical base of the membership will surely influence future international projects within KBS and hopefully change the balance between north and south in social alcohol research. New "comparative understandings of alcohol use and alcohol problems" will have to be developed. It seems also that many of the new members may put politics more firmly on the research agenda. In the globalized world, there will be a demand for new social and cultural research, exploring the limits of "global solutions to global problems" (see "Addiction-A Global Problem," 2012).

This new internationalism, in combination with the journal that gives the society a public face, could imply an internationally more influential role for KBS, both in substance use research and for policies.

The time is right for this journal, which has impressive potential resources, if it can both mobilize the internationally influential members and promote publication from low- and middle-income countries, in critical, equal and open search for new knowledge.

\section{Reference}

Addiction-A global problem with no global solution [Editorial]. (20I2, Jan 7). Lancet, 379, 2.

Kerstin Stenius, PhD

IJADR Advisory Board Editor of Nordic Studies on Alcohol and Drugs Guest Professor, SoRAD, Stockholm University, Sweden; Senior Researcher, National Institute for Health and Welfare, Helsinki, Finland 